\title{
Syntactic Deviations in the Novel The Sound and the Fury
}

\author{
Pooria Alirezazadeh \\ Department of English Studies, Islamic Azad University \\ Shahreza Branch, Shahreza, Esfahan, Iran \\ E-mail: palirezazadeh@yahoo.com \\ Mohammad Reza Talebinezhad \\ Department of English Studies, Islamic Azad University \\ Shahreza Branch, Shahreza, Esfahan, Iran \\ E-mail: talebinejad@iaush.ac.ir
}

Doi:10.7575/aiac.alls.v.5n.5p.222

Received: 03/08/2014

URL: http://dx.doi.org/10.7575/aiac.alls.v.5n.5p.222

Accepted: 10/09/2014

\begin{abstract}
This article looks at William Faulkner's work The Sound and the Fury. The goals are to investigate different types of syntactic deviations in the novel, and how these deviations helped the writer to create a literary work in the field of modernist literature and stream of consciousness. To this end, the theoretical framework for linguistic deviations proposed by Leech (1969) has been chosen. Most prior researches on linguistic deviations especially syntactic deviations focused on poetic text and classic prose. The present study was designed to address syntactic deviations in modern prose, and it highlights the role of syntactic deviations in modernist literature and psychological novel.
\end{abstract}

Keywords: Syntactic Deviations, Stream of Consciousness, Bad or Incorrect Grammar, Syntactic Rearrangement or Hyperbaton.

\section{Introduction}

One of the most significant current discussions in the field of literature and linguistics is study of modern English literature, in recent years, there has been an increasing interest in analyzing different aspects of literary works known as modern English literature. In many cases a debate was taking place between scholars and researchers in terms of the specific and unique features of this literary genre, and they have drawn our attention to examine how language and literature properties are structured to create what we know as modern English literature.

Abrams (1999) describes the term Modernism as a phenomenon after World War I (1914-18) in literature and other arts with specific features introducing new subject, form, concept and style, he argues that the most distinguishing feature of Modernism is breaking traditional rules of western art and literature. Undoubtedly, modernist literature includes both poetry and prose, but this study puts the focus of attention on the modernist prose especially modernist novel. The Sound and the Fury (1995) has been known as one of the literary masterpieces written in the realm of modernist literature. Guerin, Labor, Morgan, Reesman and Willingham (2005) maintain that modernist literature uses psychological techniques such as stream of consciousness writing, and focuses on impressionism and subjectivity, they introduce Franz Kafka, William Faulkner, James Joyce and Virginia Woolf as the most outstanding figures of modernist literature.

The present study was structured to explore syntactic deviations in the novel The Sound and the Fury by Faulkner (1995), from a literary viewpoint, this novel has been considered as a masterpiece of modernist literature written in the realm of stream of consciousness, owing to this fact, it would be worthwhile to look at characteristics of this writing style. According to Abrams (1999) the term stream of consciousness introduced by the psychologist William James has been employed as a specific method of narration in literature dealing with reproducing continuous flow of character's mental process without the writer's intervention. Chatman (1980) identifies stream of consciousness as a writing style going beyond syntax, he argues that stream of consciousness "contains the arrangement of semantic elements according to the principle of free association" (p.189). Luebering (2011) draws our attention to the concept of psychological novel, he maintains that:

As the psychological novel developed in the 20th century, some writers attempted to capture the total flow of their characters' consciousness, rather than limit themselves to rational thoughts. To represent the full richness, speed, and subtlety of the mind at work, the writer incorporates snatches of incoherent thought, ungrammatical constructions, and free association of ideas, images, and words at the pre-speech level. (p. 171) 
Steinberg (as cited in Chang, 1993) describes the linguistic features of stream of consciousness as lack of punctuation, short sentences, fragmented syntax, abrupt shifts in chain of events and random associations. Based on the research objective, the theoretical framework proposed by Leech (1969) has been taken, due to the fact that syntactic deviations play the main role in the present study, we need to take a deeper and closer look at the concept of linguistic deviations in general and syntactic deviations in particular from Leech's viewpoint.

\subsection{Linguistic Deviations}

Leech (1969) believes that linguistic deviations are an undeniable aspect of poetry, they can be considered as the most distinguishing factor between poetry and the other types of text, he continues that in order to create a poetry, the poet needs to deviate from norms and principles of standard language, this deviation leads to produce an artistic work. From his own viewpoint, there are eight types of linguistic deviation named as follows:

Lexical Deviation, Grammatical Deviation, Phonological Deviation, Graphological Deviation, Semantic Deviation, Dialectical Deviation, Deviation of Register, Historical Period. As suggested by Leech (1969), grammatical deviation has two aspects, morphology and syntax, syntactic deviation is divided into two main types, bad or incorrect grammar and syntactic rearrangement or hyperbaton. As indicated by the name, we deal with deviations occur within syntax and structure of a sentence. Plett (2010) defines syntactic deviation as "transformational operations of addition, deletion, rearrangement and replacement of syntactic components" (p.183).

A key point to bear in mind is that Leech (1969) identifies linguistic deviations as distinguishing factor of poetry, but he draws our attention to employing grammatical deviations especially syntactic deviations in prose, he introduces interior monologue employed by James Joyce in the novel Ulysses as one of the best examples of deviation from syntactic norms of prose.

To date a considerable amount of literature has been published on linguistic deviations in the literary works, most studies have been carried out in the field of poetic works. So far, however, there has been little discussion about seeking linguistic deviations in prose. Masanori (2011) studied different types of linguistic deviations in the novel Oliver Twist employed by Dickens (1838), Nabian and Iraji (2013) conducted a study to find different types of deviations in the novel Blind Owl by Hedayat (1937). They tried to analyze frequency of linguistic deviations in the light of Leech's framework (1969), they acknowledged that there are eight types of linguistic deviations in the novel, and the highest frequency belongs to grammatical deviation. Ouameur (2013) investigated different types of linguistic deviations in Dickens's Hard Times, he concluded different types of linguistic deviations helped the writer to portray Victorian society and different aspects of the characters involved in the novel, these deviations also helped to develop the plot of the story. The matter of fact is that the researches to date have tended to focus on classis literature rather than modernist literature, to this end, the present study was designed to address syntactic deviations in the novel The Sound and the Fury by Faulkner (1995) known as one of the most outstanding literary works in the field of psychological literature and stream of consciousness.

\subsection{Research Questions}

The main questions addressed in this study are as follows:

1) What types of syntactic deviations are employed by Faulkner (1995) in the novel The Sound and the Fury?

2) To what extent do these syntactic deviations help to create a novel classified as modernist literature in the field of stream of consciousness?

\section{Methodology}

\subsection{Source of Data}

The novel is divided into four chapters. As Fargnoli, Golay and Hamblin (2008) pointed out, the first three chapters of the novel are the best example of stream of consciousness portrayed by Faulkner (1995). In order to seek answers to the research questions, $30 \%$ of each chapter has been analyzed to obtain samples of syntactic deviations. This percentage includes the characters' interior monologues and dialogues.

\subsection{Procedure}

With regard to the nature of the present study, analytical descriptive method was selected as the best strategy to seek the issue in question. The samples extracted from three chapters of the novel were analyzed to identify different types of syntactic deviation on the basis of framework proposed by Leech (1969). Frequency and percentage of each type of syntactic deviation obtained for each chapter of the novel were calculated throughout data analysis process.

\section{Results and Data Analysis}

As mentioned earlier, in order to address the research questions, the first three chapters of the novel known as the best example of stream of consciousness writing style have been chosen, $30 \%$ of each chapter has been analyzed according to Leech's classification of syntactic deviation. Types, frequencies and percentages of syntactic deviations obtained from data analysis are summed up in tables 1 to 3 . 
Table 1. Frequency and Percentage of Syntactic Deviations in Chapter One

\begin{tabular}{cc}
\hline & F. (\%) \\
\hline Bad or Incorrect Grammar & $99.99 \%$ \\
\hline $\begin{array}{c}\text { Syntactic Rearrangement } \\
\text { or Hyperbaton }\end{array}$ & $1.1 \%$ \\
\hline
\end{tabular}

The table above illustrates the frequency and percentage of syntactic deviations in chapter one.

Table 2 Frequency and Percentage of Syntactic Deviations in Chapter Two

\begin{tabular}{cc}
\hline & F. (\%) \\
\hline Bad or Incorrect Grammar & $99.99 \%$ \\
\hline $\begin{array}{c}\text { Syntactic Rearrangement } \\
\text { or Hyperbaton }\end{array}$ & $1.1 \%$ \\
\hline
\end{tabular}

The table above illustrates the frequency and percentage of syntactic deviations in chapter two.

Table 3. Frequency and Percentage of Syntactic Deviations in Chapter Three

\begin{tabular}{cc}
\hline & F. (\%) \\
\hline Bad or Incorrect Grammar & $100.100 \%$ \\
\hline $\begin{array}{c}\text { Syntactic Rearrangement } \\
\text { or Hyperbaton }\end{array}$ & $0.0 \%$ \\
\hline
\end{tabular}

The table above illustrates the frequency and percentage of syntactic deviations in chapter three.

\section{Discussion and Conclusion}

According to the theoretical framework proposed by Leech (1969), there are two types of syntactic deviation, bad or incorrect grammar, syntactic rearrangement or hyperbaton, the purpose of this study is to explore deviational patterns in The Sound and the Fury (1995) and what these patterns can tell us about the use of syntactic deviations in stream of consciousness as a writing style.

\subsection{Samples of Chapter One}

As Volpe (2003) reminds us, the opening chapter of the novel is narrated through Benjy's idiot mind, he has some difficulties with making judgments and understanding relationship between different ideas and events. Take the following samples as illustrations:

$$
\begin{array}{ll}
\text { - } & \text { Maybe we can find one of they balls. Here. Here they is. } \\
\text { - } & \text { "He want to go out doors." Versh said. } \\
\text { - } & \text { "I is done it. Hush, now." Luster said. } \\
\text { - } & \text { "He dont know what he want to do." }
\end{array}
$$

The highlighted items in the above samples reflect what we can label as bad or incorrect grammar. "they balls" is the incorrect form of "their balls". A closer look at these samples confirms that mismatches between subjects and main verbs lead us to treat these items as syntactic deviation.

I is.......... am

They is..........They are

He don't...........He doesn't

The following sample extracted from chapter one is an example of syntactic rearrangement:

- Versh said, Your name Benjamin now. You know how come your name Benjamin now.

The subject "your name" must precede the verb "come", but the arrangement of this sentence deviates from the standard norm.

\subsection{Samples of Chapter Two}

According to Volpe (2003), the second chapter of the novel is narrated through Quentin's obsessive mind. Consider the following excerpts from the second chapter: 
- Hats not unbleached and not hats. In three years I can not wear a hat. I could not. Was. Will there be hats then since I was not and not Harvard then. Where the best of thought Father said clings like dead ivy vines upon old dead brick. Not Harvard then. Not to me, anyway. Again. Sadder than was. Again. Saddest of all. Again.

- Under the window we could hear the car leaving for the station, the 8:10 train. To bring back cousins. Heads. Increasing himself head by head but not barbers. Manicure girls. We had a blood horse once. In the stable yes, but under leather a cur. Quentin has shot all of their voices through the floor of Caddy's room

There is no mystery in the fact that the disjointed syntax of both samples is the best example of bad or incorrect grammar. The most frequent use of incomplete and subjecless sentences, lack of cohesion and finite elements, overlap between sentences are unique Faulkner's techniques to portray an obsessive mind in the second chapter. The most striking and obvious point derives from these samples is lack of cohesion, according to Halliday and Hassan (1976), "the concept of cohesion is a semantic one; it refers to relations of meaning that exist within the text, and that define it as a text" (p.4). Eggins (1994) argues that "when we say the clauses don't hang together, we are reaching to two dimensions of the paragraph: its contextual properties: what we call its coherence; and its internal properties: what we call its cohesion" (p.87). Taking these ideas collectively, Faulkner (1995) made an attempt to portray an obsessive mind by shifting from a stream of thoughts to another stream of thoughts, besides, breaking the rules of a standard text as one of the unique features of modernist literature can be seen easily in the samples of chapter one and chapter two.

Hats (are/were) not unbleached and (are/were) not hats.

The finite element "be" removed in the sentence above indicates another form of incorrect structure.

- $\quad$ "Kenny," the second said. Say it to Father will you I will am my fathers Progenitive I invented him created I him Say it to him it will not be for he will say I was not and then you and I since philoprogenitive

The third sample of chapter two reflects another example of syntactic rearrangement, the highlighted sentence deviates from English standard word order known as SVO (subject+ verb+ object).

Created I him.........I created him

VSO.........SVO

\subsection{Samples of Chapter Three}

As confirmed by Volpe (2003), the third chapter is narrated through Jason's mind, unlike the previous chapters, the third chapter is easy to follow, and to a certain extent, it dose not have a puzzling and complex structure like two previous chapters. Consider the following samples from chapter three:

- $\quad$ Once a bitch always a bitch, what I say. I says you're lucky if her playing out of school is all that worries you.

• I reckon that's your school costume, is it?" I says. "Or maybe today's a holiday?" "Just a half a cup, Dilsey," she says. "Please."

Another example of bad or incorrect grammar can be seen in the samples above.

I says..........I say

Consider the tag question in "I reckon that's your school costume, is it?", by principle, the tag question in such structure must be negative but it is positive and another example of bad or incorrect grammar.

I reckon that's your school costume, is it?......... I reckon that's your school costume, isn't it?

Returning to the research questions, the significant findings to emerge from the present study can be divided into two main aspects, types of syntactic deviations, and possible explanations for using these deviations in the main text by the writer. As mentioned earlier, in most previous studies, researchers have focused on linguistic and syntactic deviations in poetic texts and classic prose, the findings of the current study do not support the previous researches carried out in the field of poetry, this inconsistency may be due to different language of poetry and prose, to some extent, the findings further support the idea of Ouameur (2013) who suggested the linguistic deviations employed by Dickens in Hard Times helped the writer to develop different aspects of characters and the plot of the story, by the same token, syntactic deviations in Faulkner's novel helped him to develop and depict a psychological novel in the field of modernist literature and stream of consciousness writing style, chaotic atmosphere, an idiot's stream of thoughts, an obsessive man's confusing language, people from lower social class have been portrayed successfully by use of syntactic deviations.

The obvious response to the first question is that both types of syntactic deviation have been found in data analysis process, as shown in tables 1 to 3, the highest frequency belongs to bad or incorrect grammar, based on analysis of samples extracted from the first three chapters of the novel, frequency of syntactic rearrangement or hyperbaton is not statistically significant. It is difficult to explain this result, but it may be related to differences between poetry and prose in terms of employing syntactic deviation especially syntactic rearrangement. Leech (1969) believes that arranging syntactic elements in an irregular order or what we know as hyperbaton is considered as a freedom in poetic language, 
to put it another way, a poet has more freedom to use irregular syntactic elements rather than a writer in other types of text.

We must also consider the familiar notion of language and social class, as Trudgill (2000) pointed out, grammatical deviations help reader to identify the speaker's social class, this technique has been used by Faulkner (1995) abundantly in the novel, such as I says, he don't, I is, he be gone etc. these deviations demonstrate that the speakers are from a lower social class, and we can conclude that Faulkner (1995) had succeeded to convey the concept of language and social class.

Turning now to the second question, perhaps the major finding in this study is demonstrating the close link between syntactic elements and frequent use of deviations from these norms in the modernist literature especially psychological novel. Speaking to this technically, as discussed earlier, The Sound and the Fury (1995) is a psychological novel in the field of modernist literature and stream of consciousness, ungrammatical structures and syntactic deviations have been considered as the most distinguishing characteristics of such literary works. These deviations also illustrate breaking traditional rules of old literature, Faulkner (1995) had depicted collapse of a family in The Sound and the Fury successfully, narrating the story by an idiot, an obsessive mind, more detailed description of events, chaotic situations, disorder and turmoil are the most technical aspects of the novel. Syntactic deviations and disjointed syntax have played a significant role in creating such an atmosphere.

\section{References}

Abrams, M. H. (1999). A glossary of literary terms. ( $7^{\text {th }}$ ed.). Massachusetts: Heinle \& Heinle, a devision of Thomson Learning.

Chang, S. (1993). Modernism and the nativist resistance: Contemporary Chinese fiction from Taiwan. Durham: Duke University Press.

Chatman, S. (1980). Story and discourse: Narrative structure in fiction \& film. New York: Cornell University Press.

Eggins, S. (1994). An introduction to systemic functional linguistics. London: Continuum International Publishing Group.

Fargnoli, A. N. \& Golay, M. \& Hamblin, R. W. (2008). Critical companion to William Faulkner: A literary reference to his life and work. New York: Facts On File, Inc.

Faulkner, W. (1995). The Sound and the Fury. New York: Vintage.

Guerin, W. L. \& Labor, E. \& Morgan, L. \& Reesman, J. C. \& Willingham, J. R. (2005). A handbook of critical approaches to literature. New York: Oxford University Press.

Halliday, M. A. K. \& Hasan, R. (1976). Cohesion in English. London: Longman.

Leech, G.N. (1969). A Linguistic Guide to English Poetry. London: Longman.

Luebering, J. E. (Ed.). (2011). English literature from the 19th century through today. New York: Britannica Educational Publishing, Inc.

Masanori, M. (2011). Types of Linguistic Deviation in Oliver Twist. [Online] Available: www.irjabs.com (May 12, 2014)

Nabian, P. \& Iraji, M. (2013). The Linguistic Study of Prose Style in "Buf-e-Kur" by Sadegh Hedayat an Iranian Writer with respect to Frequency of Different Types of Deviation. International Research Journal of Applied and Basic Sciences, 4 (6), 1454-1460.

Ouameur, M. D. (2013). Linguistic Deviation in Hard Times. [Online] Available: bu.univ.ouargla,dz (May 12, 2014)

Plett, H.F. (2010). Literary Rhetoric Concepts-Structures-Analyses. Leiden, Boston: Brill.

Trudgill, P. (2000). Sociolinguistics: An Introduction to Language and Society. London: Penguin.

Volpe, E. L. (2003). A reader's guide to William Faulkner: The Novel. Syracuse: Syracuse University Press. 